\title{
Aesthetic education and methods of aesthetic development in children with disabilities
}

\author{
Nabiyeva Gulshod Ikhtiyorovna ${ }^{2}$ \\ ${ }^{1}$ Student of Tashkent State Pedagogical University \\ Email:ngulshoda@list.ru
}

\begin{abstract}
Aesthetic education and its importance in human life, its role in our social life, psychological and pedagogical classification are given basic concepts. Aesthetic taste is the formation of a sense of beauty in the mind, the means of aesthetic education, the features of aesthetic education, the difficulties in solving aesthetics in children with disabilities and their solutions, the importance and methods of aesthetics in developing the talents and abilities of children with disabilities: in particular innovative technologies.
\end{abstract}

Keywords: aesthetics, aesthetic education, aesthetic feeling, family, children with hearing impairments, visual arts, deaf pedagogue, speech, cognition.

\section{INTRODUCTION}

Aesthetic perceptions are also among the highest moral perceptions. By aesthetic sense we mean the perception of beauty, the enjoyment of beauty, and the pursuit of beauty. Aesthetic feeling is a feeling that is common to all people. The surrounding natural landscapes are the first source of our aesthetic feelings. For example, the mountain scenery in the spring, the high snow-capped peaks from afar, give a person a sense of aesthetic pleasure. A rainbow, a flowerbed, or a butterfly that glows in different colors after the rain, and the blue cotton fields, which are as invisible as the sea, and the field hills, which look beautiful in the distance. 'diradi. People react to various facts of life and the reflection of the art of the ulama as some kind of beauty or ugliness as tragic or ridiculous, noble and ugly, elegant or crude. These feelings are expressed in aesthetic tastes at appropriate prices and are forgiven in a state of distinctive artistic enjoyment. The sources of aesthetic feelings are many and varied. For example, in addition to enjoying natural landscapes, works of fine art, works of art, music and sculpture, architecture and architecture also create an aesthetic feeling. In addition, the way people interact with each other can be a source of aesthetic feelings. For example, a person who speaks rudely is hated, but a person who speaks politely, appropriately and politely enjoys it. He wants to imitate such people. In general, a person's aesthetic feelings are complex emotions with many sources.

\section{THE RESULTS}

The task of "Aesthetic Education" is the formation of aesthetic taste, its elimination of various flaws and shortcomings. Aesthetic education - Latin "estesio" means "I feel beauty" - to teach students to understand, comprehend and comprehend the beauties of vocabulary, nature, social and labor relations and life, to develop their artistic taste, to instill in them awakening a love for beauty is a pedagogical process aimed at cultivating their ability to create beauty. Aesthetic education helps to develop and develop a sense of beauty. Man always strives to build his life on the basis of beauty. Aesthetic education is closely related to moral, intellectual, legal, environmental, social and labor education. The love of nature, literature, theater, music, poetry, fine arts, etc., contributes to the full development of the individual. The essence of aesthetic education is that it determines the attitude to beauty. A high cocktail culture cannot be achieved without developing a sense of beauty. The beauty that emerged in cocktail activities has evolved throughout all stages of historical development, and it has begun to influence cocktail activities themselves. The importance, function and necessity of each product (commodity) made 
in the process of labor is assessed not only in terms of meeting the natural needs of man, but also in terms of its beauty. Beauty is life itself, the result of nature and human labor, the perfection of human relationships. Aesthetic knowledge is formed on the basis of specific educational activities - competitions, quizzes, celebrations, exhibitions, etc. Students demonstrate their abilities in a variety of artistic activities. At an early age, "all children are painters without exception" (K.D. Ushinsky), "every child is a poet" (V. Sukhomlinsky).

Aesthetic education (delicacy) is a long-term process of formation and development of aesthetic consciousness, attitudes and aesthetic activity of the individual, which has different stages and levels, determined by age and social factors. Aesthetic education is aimed at mastering the aesthetic culture of the individual and is carried out using various forms and methods. The means of aesthetic education are the factors used in the pedagogical process aimed at organizing the life, nature, beauty of art and children's artistic activity, selected from the environment in order to educate students in the spirit of love of beauty.

Fiction has endless possibilities in aesthetic education. It teaches students a deeper understanding of life. The works of art, which reflect the beauty of the universe and man, courage, bravery, and high human ideals, have inspired people to feel beauty and strive for it. On the contrary, ideologically lowlevel works diminish the minds of students, distract them from true beauty, weaken their desire to love beauty, and degrade their taste.

The first school of aesthetics is the family. It is the first step in teaching children to understand the subtleties of family relationships, homework, their unity, harmony, orderly arrangement, care, cleanliness and cleanliness. The decoration of the school, the school's memorial and excellence corner, the events, the holiday contests, etc. all have a great impact on the beauty education of children directly. The beauty of life is cleanliness and order. It is also important to keep the classrooms clean, to organize a nature corner, to exhibit students' creative work, and to update the board system. Fiction has endless possibilities in nurturing sophistication. It teaches students a deeper understanding of life. Students will be introduced to Uzbek and foreign literature. The more students read poems, stories, examples of folklore - proverbs, parables, fairy tales, epics, songs, short stories and novels, the stronger their desire for beauty. The analysis of the life and creative activity of poets and writers, acquaintance with their works, expands the scope of knowledge of students, improves their emotions and language skills. Literature classes also help students learn about beauty. Students memorize prose and poems, which in turn develops a culture of artistic discourse.

Aesthetic education (delicacy) is a long-term process of formation and development of aesthetic consciousness, attitudes and aesthetic activity of the individual, which has different stages and levels, determined by age and social factors. Aesthetic education is aimed at mastering the aesthetic culture of the individual and is carried out using various forms and methods. The means of aesthetic education are the factors used in the pedagogical process aimed at organizing the life, nature, beauty of art and children's artistic activity, selected from the environment in order to educate students in the spirit of love of beauty.

Fiction has endless possibilities in aesthetic education. It teaches students a deeper understanding of life. The works of art, which reflect the beauty of the universe and man, courage, bravery, and high human ideals, have inspired people to feel beauty and strive for it. On the contrary, ideologically lowlevel works diminish the minds of students, distract them from true beauty, weaken their desire to love beauty, and degrade their taste.

The first school of aesthetics is the family. It is the first step in teaching children to understand the subtleties of family relationships, homework, their unity, harmony, orderly arrangement, care, cleanliness and cleanliness. The decoration of the school, the school's memorial and excellence corner, the events, the holiday contests, etc. all have a great impact on the beauty education of children directly. The beauty of life is cleanliness and order. It is also important to keep the classrooms clean, to organize a nature corner, to exhibit students' creative work, and to update the board system. Fiction has endless possibilities in nurturing sophistication. It teaches students a deeper understanding of life. Students will be introduced to Uzbek and foreign literature. The more students read poems, stories, examples of folklore - proverbs, parables, fairy tales, epics, songs, short stories and novels, the stronger their desire for beauty. The analysis of the life and creative activity of poets and writers, acquaintance with their works, 
expands the scope of knowledge of students, improves their emotions and language skills. Literature classes also help students learn about beauty. Students memorize prose and poems, which in turn develops a culture of artistic discourse.

Nurturing aesthetics in children is very important and fun. Their strong interest in bright and diverse colors, their desire to decorate and paint, can be seen in the fact that the walls even draw on objects and furniture. Properly assessing and directing these interests will allow them to showcase their hidden talents. Aesthetic education has such a power that the plot, event, perception depicted in works of art (artistic depiction) is processed from the aesthetic sense in the imagination, imagination, experience, and becomes their own experience.

Observations of children with visual impairments show that they are unable to express themselves as healthy peers from the rights of physical and mental activity, such as play, study, and work, to the extent that they are able to use their abilities and strengths to the best of their ability. spend on acquiring skills and abilities. As a result, they achieve high results in this area. For example, there are people who have a place in the arts and literature. Olga Skorokhodova, who has a visual and hearing impairment, has been widely used in special education for her invaluable scientific work on how to perceive, imagine and explain the world around her. Ballerina Lina Poe loses her sight at the age of 21. Lina became a well-known sculptor due to her talent and aspiration. Lina A.S. Pushkin created portraits of A.P. Chekhov. The number of Lina Poe's works of art has reached 100.

Aesthetics is very important for children between the ages of two and six to seven. Preschool educators need to introduce children to all types of art, regardless of their abilities, and ensure the full development of artistic ability. Children's art includes a wide variety of arts, including music, art, and theater. Specificity in the cognitive process of children with hearing impairment and a sharp decrease in hearing complicate the process of aesthetic education. A.A. Wenger, A.P. Gozova, T.V. Rozanova Psychological research of N.M. Solovev shows that the deaf children's ability to see and perceive tactilevibration lags behind their hearing peers - the result of deafness and delayed development of oral speech. Drawing skills are delayed due to movement, especially for small motor skills. Hearing impairment deprives children of the opportunity to understand music as an art genre, and leads to a unique musical upbringing for deaf and hard of hearing preschool children. The subject of preschool deaf pedagogy defines the following tasks of aesthetic education:

- Aesthetic perception in children,

- development of aesthetic feelings and concepts;

- to cultivate artistic taste, to develop artistic ability, to cultivate the need to express one's thoughts and feelings through art;

- Speech development in connection with aesthetic education.

Aesthetic education of children with hearing impairments is carried out in conjunction with the development of speech. In each lesson, the deaf educator and educator form the vocabulary needed to organize the speech, as well as the vocabulary needed for a particular type of activity. For example, activities related to visual activities include practical skills as well as materials (clay, paper glue), movements (making, drawing, painting, cutting, gluing), equipment (pencil, mo ' pencil, felt-tip pen) and expressions such as "Draw a picture of a sphere", "I drew a picture of a sphere", "You can draw a picture of a sphere". There are also concepts such as beautiful, ugly, bright, appropriate, and thorough to evaluate visual activity. Necessary words are conveyed to children orally and in writing, and are reinforced in their practical activities. In the visual arts activities, children are introduced to a variety of visual arts that they can understand. An educator who looks at a picture with children shows them enjoyment, teaches them how to evaluate activities with words, and thus develops children's speech. Children in special preschools are introduced to literary works, read fairy tales, find riddles and memorize poems. The deaf educator and educator, while emotionally telling the stories and tales, take the children into the world of heroes and evoke positive emotions in them. In this way, children's speech is enriched with new words and phrases, and their perception of existence is strengthened..

\section{CONCLUSIONS}

In the process of teaching and educating students, it is important to use a variety of methods to nurture their aesthetic tastes. Didactic games can achieve this goal in the course of the lesson, which 
requires the use of innovative and completely new effective methods. The organization of lessons or classes in a completely different way, a separate approach to each lesson will help to fully implement the tasks of education. Innovative methods are important for special secondary school students. Because the main problem in the education and upbringing of such students is the lack of interest. You can't just show them or explain them. For example, teaching a native speaker to write beautifully is difficult to explain, and can take years. And by cultivating aesthetic pleasure, this work is made a little easier. This can be achieved by allowing them to practice sewing, sculpture, fine arts and handicrafts in a playful way to develop fine motor skills.

\section{REFERENCES}

[1] "General psychology" F.I.Khaydarov, N.I. Khalilov

[2] "Special pedagogy" L.P. Muminova

[3] Special Psychology Textbook L.R. Muminova, Sh.M.Amirsaidova

[4] "Pedagogy" M.X. Toxtaxodjayeva, S. Nishonova,

[5] Abu Nasr Faroobi. M. Mahmudov - T., People's Heritage, compiler of "The city of noble people". 1993.

[6] Abdurahmanov F., Davletshin M. How to communicate and approach people. - Tashkent, 1996.

[7] S. Adizova "Psychological diagnosis and correction of interpersonal relationships of teachers." - T., 2002.

[8] Adizova T., Usmanova E. Psixologicheskie trudnosti v obuchenii mladshix shkolnikov. T. 1995.

[9] Axmedjanov E.R. "Psychology test" - 1996.

[10] Aytmetova S.Sh. Features of mental development of students in a special school 